\section{Em busca da liberdade do ir-e-vir}

\author{
Eduardo Marandola Jr. *
}

KAPLAN, Daniel; MARZLOFF, Bruno. Pour une mobilité plus lire et plus durable. Limoges: FYP, 2008. 86p.

KAUFMANN, Vincent. Les paradoxes de la mobilité: Bouger, s'enraciner. Lausanne: Presses polytechniques et universitaires romandes, 2008. 115p.

ORFEUL, Jean-Pierre. Une approche laïque de la moibilité. Paris: Descartes \& Cie, 2008. 173p.

ORFEUL, Jean-Pierre. Mobilités urbaines: l'âge des possibles. Paris: Les Carnets de l'Info, 2008. 254p.

$\mathrm{Na}$ reflexão contemporânea sobre mobilidade, a contribuição francesa parece acrescentar um elemento diferente ao caldeirão dos feiticeiros. Se a bibliografia americana está muito preocupada com as transformações produzidas pela hipermobilidade, procurando avaliar prós e contras, muito conectada às transformações nos transportes e comunicações, a produção recente na França levanta outras questões que constituem desafios para os estudos populacionais.

É isso que a leitura de alguns dos títulos recentemente publicados (em 2008) nos provoca a pensar. Vou comentar quatro destes, pois trazem diversidade numa mesma direção.

O primeiro é Pour une mobilité plus lire et plus durable, de Daniel Kaplan e Bruno Marzloff. Kaplan é o fundador e diretor da Fing (Fondation pour I'Internet Nouvelle
Génération), instituição que promove inovações e soluções em tecnologias da informação, e Marzloff é sociólogo, presidente do Grupe Chonos, ${ }^{1}$ além de professor da Paris 1. Ambos militam pelo Sustainable-mobility.org, um centro de pesquisa em mobilidade de emissão zero.

O livro de Kaplan e Marzloff, portanto, é um manifesto e um elogio à mobilidade sustentável, que, para os autores, precisa ser ao mesmo tempo justa e alcançar toda a sociedade. Com o foco em experiências sustentáveis que utilizam tecnologias limpas, eles discutem projetos de cidades limpas e cidades do automóvel mais inteligentes, como os projetos com carros elétricos reduzidos apenas à sua função de locomoção: sem luxo ou adicionais, eles poupam energia e espaço por sua versatilidade e seu "design verde" compacto.

O tema do livro é "por uma mobilidade livre e sustentável", pois os autores apregoam que o sentido da mobilidade é a liberdade na cidade, ligada diretamente à democracia e à qualidade de vida e ambiental.

Eles lembram que a grande dificuldade de efetivar uma mobilidade sustentável é um embate de valores entre a individualização do estilo de vida, centrado no automóvel, e uma coletivização do transporte. São ideias divergentes que colocam um paradoxo central no debate urbano: a flexibilização dos movimentos leva à liberdade, à diversidade, pois conduz ao uso do automóvel. Quem depende de transporte coletivo fica preso e limitado no tempo e no espaço.

Liberdade, solidariedade e sustentabilidade da mobilidade urbana estão ligadas, para os autores, a uma densificação dos serviços e da população. É na concentração, nas cidades e bairros autossuficientes, que estaria a possibilidade de reinventar a mobilidade urbana. Eles citam exemplos de como a mudança nos valores da mobilidade são imprescindíveis para que se possa mudar a matriz modal, favorecendo o uso de transportes coletivos e de articulações mais inteligentes. É uma bravata contra a cidade

\footnotetext{
* Geógrafo, Núcleo de Estudos de População, Universidade Estadual de Campinas (Nepo/Unicamp).

${ }^{1}$ Grupo dedicado ao estudo da mobilidade urbana (http://www.grupo-cronos.com/).
} 
dispersa, em favor da cidade compacta, a qual potencializa recursos e promove a proximidade cultural e social.

Este tipo de movimento está crescendo no mundo todo e, por isso, vale à pena acompanhar suas repercussões e as efetividades das propostas concretas de outras formas de mobilidade urbana e seus possíveis impactos na distribuição espacial da população.

O segundo livro é Les paradoxes de la mobilité, de Vicent Kaufmann. Sociólogo do Laboratoire de Sociologie Urbaine, da École Polytechnique Fédérale de Lausanne, Kaufmann desenvolve alguns dos paradoxos da mobilidade contemporânea, os quais se manifestam em diferentes campos. O livro está organizado em oito pequenos capítulos: 1) Sommes-nous vraiment de plus em plus móbiles?; 2) En nous déplaçant plus vite et plus loin, sommes-nous plus libres?; 3) Les manières de se déplacer se multiplient et la société change; 4) Mobilité et inégalités; 5) Comment la mobilité transforme la ville; 6) L'automobile, les politiques de transports urbains et la mobilité; 7) Politiques de déplacements urbains: les bonnes pratiques suisses en question; 8) Dix thèsis sur les déplacements et la mobilité.

O grande paradoxo apontado por Kaufmann é a grande mobilidade associada ao nosso modo de vida sedentário. Ideias contrárias por definição, a vida contemporânea é permeada pelo aumento dos deslocamentos (em número, distância e tempo gasto) em face do permanente e inabalável sedentarismo.

O autor defende a necessidade de pensar a mobilidade para além da questão dos transportes, bem como de considerar suas repercussões no cotidiano e nas diversas facetas da vida social. Enquanto fenômeno espaço-temporal, a mobilidade precisa ser considerada central para uma vida livre e saudável.

Assim como Kaplan e Marzloff, Kaufmann defende a rediscussão do uso do automóvel, indo contra sua generalização e favorecimento. Para isso, o autor analisa os diferentes tipos de deslocamento, buscando refletir sobre alternativas para os sistemas de transportes coletivos, mais eficientes e menos poluidores. Ele também frisa a importância de uma pré-disposição da parte das pessoas em usarem e possuírem automóveis, o que precisa ser combatido em prol da mobilidade mais eficiente.

Para tanto, o modelo suíço é seu baluarte, tomando Berna e Zurique como exemplos de eficiência nos transportes públicos, além das transformações de alguns bairros parisienses, onde formas de mobilidade alternativa têm produzido bons resultados.

É baseado nestes e em outros exemplos que Kaufman termina o livro com dez teses sobre os deslocamentos e a mobilidade: 1) a mobilidade é ambivalente, mas assume as formas das relações sociais; 2) ser móvel não quer dizer necessariamente se mover rapidamente, nem muito; 3 ) aqueles que se movem mais rápido não são necessariamente mais livres; 4 ) a mobilidade é essencial para a inclusão social; 5) a mobilidade se estende a partir da mobilidade das pessoas; 6) por influência da mobilidade vamos abandonar muitos preconceitos; 7) deslocamentos não são lacunas que o usuário procura sanar; 8) o automóvel favorece certos deslocamentos em detrimento da mobilidade; 9) o modelo suíço de política de deslocamentos urbanos; 10) uma política justa de deslocamentos deve permitir o pluralismo.

As teses apontam, em uníssono, para a virtude da coletividade em prol de uma política de mobilidade urbana que inclua suas várias dimensões, favorecendo a liberdade, a coletividade e a diversidade de deslocamentos, sem, no entanto, priorizar o transporte individual.

Se estes dois livros têm um caráter mais reflexivo e menos técnico, com um componente social e ambiental balizares, as duas outras obras que vou comentar, ambas de Jean-Pierre Orfeuil, professor do Institut d'Urbanisme de Paris at Paris XII e diretor do Institut's Chaire pour la Ville en Movement, mergulham em questões específicas da mobilidade, suas raízes e dificuldades de planejamento e gestão.

No primeiro, Une approache laïque de la mobilité, Orfeuil procura resgatar os sentidos da mobilidade nos últimos 50 anos e suas repercussões na mobilidade contemporânea e para a mobilidade na 
França de 2050. Segundo o autor, atitudes em relação à mobilidade manifestam-se e recebem influência de várias escalas, tanto da globalização quanto da gestão cotidiana dos nossos territórios. Orfeuil enfatiza a importância da circulação nos territórios do cotidiano, bem como uma espécie de nostalgia por espaços que se gentrificam.

O crescimento da mobilidade mudou nossa visão de mundo, desvinculando o lugar de nascimento da imagem de uma âncora que nos prende ao lugar. A difusão e ampliação dos lugares é fruto destas novas mobilidades.

O autor recorre a uma perspectiva histórica da capacidade de mobilidade, passando pelos intrusos (a copresença), uso do espaço público para circulação (cada vez mais veloz), uso dos meios de transporte como status social, ilusão de velocidade do automóvel e, por fim, seu custo ambiental. A partir deles, Orfeuil encontra sentidos perenes da mobilidade e uma base para discutir formas de métrica e de planejamento de transportes.

Seu último capítulo explora o século de desenvolvimento dos transportes e da mobilidade na França, contextualizando estas críticas à mobilidade nas mudanças ambientais globais e nas transformações das relações internacionais e na própria distribuição espacial da população. Seu exercício de pensar o cenário de 2050 é instigante na medida em que nos força a pensar um futuro que comumente não faz parte da gestão ou do planejamento urbano. Mesmo para os estudos de população, afeitos a projeções, não temos nos sentido seguros para pensar processos e dinâmicas de 50 anos à frente. A provocação de Orfeuil nos faz, portanto, lançar um sobrevoo sobre sentidos e perspectivas para planejar ações práticas em busca de mobilidades melhores.

Este esforço é tanto mais válido quando lemos seu outro livro, também de 2008: Mobilités urbaines: l'âge dês possibles. O livro está dividido em cinco capítulos, além das conclusões: 1) Posséder, emprunter, recourir à um service: l'âge de l'accès signe-t-il la fin de l'ère de la propriété dês biens?; 2) Lês objets et nous; 3) Lês déplacements em France aujourd'hui;
4) Quelles solutions si la mobilité devient plus difficile ou plus coûteuse?; 5) Alors, demain?

Estes capítulos expressam a oscilação do duplo movimento do livro: mostrar a sociedade da mobilidade como a era do acesso, a era das possibilidades, ao mesmo tempo em que busca soluções práticas para seus problemas e dificuldades.

Apoiado em uma sólida perspectiva teórica (em parte desenvolvida em Une approche laïque de la mobilité), Orfeuil trafega por estes polos com desenvoltura, apresentando um quadro teórico e prático instigante para pensar a França, em primeiro plano, e os demais países que passam por processos semelhantes, como consequência.

Enquanto era dos possíveis, a liberdade da mobilidade é novamente trazida à tona como um elemento central na discussão dos deslocamentos. Seu impedimento é uma forma de limitar o ir-e-vir, e por isso precisa ser combatida com tecnologias e estratégias social e ambientalmente justas. Orfeuil não faz disso, no entanto, um argumento banal: investiga em profundidade os sentidos implícitos nestas práticas, trazendo um quadro contemporâneo bastante sofisticado e provocativo.

Estas quatro obras lançam luz sobre aspectos que tocam diretamente o estudo da mobilidade enquanto fenômeno demográfico: o impacto nas populações, suas dificuldades e possibilidades de deslocamento pelo espaço urbano. Mais do que isso, colocam em discussão aspectos centrais da forma de reprodução das cidades e sua organização interna; questões que produzem repercussões diretas e indiretas na redistribuição espacial da população.

Se a mobilidade deve potencializar a liberdade do ir-e-vir, pendularidade e deslocamentos cotidianos, cada vez mais dispersos e irregulares, impõem ao estudioso de população a necessidade de compreender e apreender cada vez melhor estes fenômenos que estão transformando as formas urbanas e os deslocamentos populacionais no espaço e no tempo.

Recebido para publicação em 27/07/2010 Aceito para publicação em 09/08/2010 